\title{
Assessment of Environmental Flow Release from DeduruOya Reservoir to Mitigate Possible Impacts on Downstream Ecosystem
}

\author{
M.M.J.G.C.N. Jayasiri*, N.D.K. Dayawansa ${ }^{1}$ and E.R.N. Gunawardena ${ }^{1}$
}

\author{
Postgraduate Institute of Agriculture \\ University of Peradeniya \\ Sri Lanka
}

\begin{abstract}
River ecosystems are interlinked with river hydrology. However, construction of dams can modify the natural flow patterns which can lead to unpredictable consequences. Environmental flow (EF) releases can restore ecosystems or reverse the already occurred degradation. Having understood the importance of EF, large number of methods has been developed to estimate the EF. The objective of this study was to make a comparison between these methods to identify the most comprehensive method and to develop a novel approach to estimate EF based on the concept of minimum information requirement. Among the EF calculation methods studied, holistic method was identified as the most reliable category and the building block methodology (BBM) was identified as the best holistic method which requires more resources or data. The new methodology developed to assess EF basically based on BBM but efforts were taken to identify minimum data requirement approaches to calculate individual water uses. It consists of the flow requirement of riverine flora and fauna, social and cultural water requirement, wetland water requirement, longitudinal connectivity, flushing flow requirement, groundwater recharge and coastal water requirement. The EF requirement of downstream of DeduruOya reservoir was estimated using the developed method. The results were compared with the EF calculated using the Sri Lanka Environmental Flow Calculator model developed by IWMI. There was a significant difference between the EF calculated using new method and the results obtained using model developed by IWMI. Hence, it is recommended to further improve and verify the findings of the new method.
\end{abstract}

Keywords: DeduruOya reservoir, Ecosystems, Downstream water requirement, Environmental flow, Environmental Flow assessment methods

\section{INTRODUCTION}

Environmental flow (EF) is defined as the quantity, quality and timing of water flows required for sustaining freshwater ecosystems and the human livelihoods and wellbeing that depend on these ecosystems (Brisbane Declaration, 2007). Simply, an EF can secure the ecosystems and ecosystem services that are essential for human wellbeing since it tends to mimic with the natural flow pattern (UNEP, 2003). Natural flow regime has its own behavior and flow functions can be violated through flow manipulations. Furthermore, the dependent downstream is interlinked with hydrology that is being changing with hydrological alterations such as dam construction and it may leads to unpredictable consequences (Richter

\footnotetext{
1 Department of Agricultural Engineering, Faculty of Agriculture, University of Peradeniya, Peradeniya, Sri Lanka

* Author of correspondence : nishanka.jayasiri@gmail.com
} 
et al, 1997; Gopal, 2013). The goal of allocating the EF under above conditions is to restore the downstream natural flow regime to an acceptable level (King et al., 2008).

Considering these importance, EFs and ecological considerations must be taken in to account seriously in development activities. For that, EF should be assessed in a reliable manner (King et al., 2008; O'Keeffe et al., 2012). Though a large number of methods are available to assess EF, the rivers have their own ecosystem characteristics, and need individual considerations when assessing EF (Silva et al., 2014). To adopt the best suit EF assessment method for a particular location, present methods are necessary to study with the aim of identifying their capabilities, strengths and weaknesses including the availability of data records and other resources to carry out an assessment successfully. Therefore, a detailed study and comparison of existing methods is a necessity to identify a best fit method for a particular location.

Reliable EF assessment methods demand data, expert knowledge, technology, time and financial resources in advance. On the other hand, less resource requiring methods are lack in reliability and accuracy. These reasons prevent a resource poor situation or data poor basin from applying reliable EF assessment methodologies. Especially, the inadequate maintenance of reliable data records is a serious and common issue faced by countries like Sri Lanka. The EF studies carried out within Sri Lanka strictly emphasized the issue of assessing EF within data scarce condition (Smakhtin and Weragala, 2005). However, O'Keeffe and Le Quesne (2009) called attention to EFs mentioning "lack of information, and lack of resources, should never be a barrier to implementation of environmental flows". Therefore, it is important to develop minimum information requirement methods to estimate EF to overcome the limitations and to make EF assessment concept more popular, acceptable and applicable.

Dam construction is the most severe issue that violates natural flow pattern and dependent ecosystems among all flow manipulations (WCD, 2000; Dyson et al., 2003). In such a situation, downstream ecosystems are possible to be under threat of losing the ecosystem functions. Therefore, releasing EF is extremely important to maintain the downstream ecosystem sustainability. It is fair for any flow alteration, including DeduruOya reservoir which has been recently constructed. By releasing EF from the beginning of the functioning of reservoir, it is possible to mitigate the ecosystem impacts from the initial stage. Proper allocation of EF can only be done if it can be estimated following a reliable methodology.

\section{OBJECTIVES}

The objectives of this study are to;

- $\quad$ compare and analyze the existing methods available for EF assessment

- $\quad$ propose a minimum information requirement approach to assess the EF requirement downstream of DeduruOya reservoir, and

- quantify the EF requirement of downstream of DeduruOya reservoir using the proposed method.

\section{METHODOLOGY}

\section{Comparison of existing EFA methods}


Existing environmental flow assessment (EFA) methodsdeveloped during 1976 to 2015 were studied in detail through a literature review. During the literature review; strengths, capabilities, weaknesses and gaps of existing EFA methods were identified and a new method to assess EF was proposed to overcome the identified gaps based on the minimum data requirement concept. In this study, most common classification of EFA methodsreported in literature such as hydrological methods, hydraulic rating methods, habitat simulation methods and holistic methods were used (Smakhtin and Anputhas, 2006; King and Tharme, 2008; Gopal, 2013; Linnansari, 2013). Tenant, Tessman, Flow Duration Curve method (FDC), Range of Variability Approach (RVA), Sustainable Boundary Approach (SBA), BC Instream and Alberta desktop method are some of examples for hydrological methods which are totally depend on past flow data records. Hydraulic rating methods assume a relationship between hydraulic parameters of the stream and flow. Table 1 shows a comparison between methods of EFA. Tick mark in the table indicates the presence of relevant feature in the method category and cross mark indicates the absence of relevant feature.

Table 1. Comparison of EFA methods

\begin{tabular}{|c|c|c|c|c|c|c|c|c|c|c|c|c|c|}
\hline 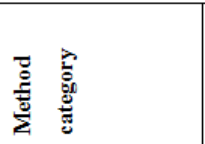 & 冚 & 竞 & .气. & 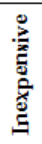 & $\frac{0}{\frac{0}{0}}$ & 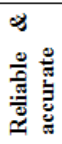 & 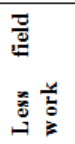 & 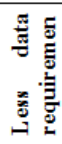 & 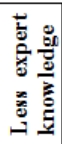 & 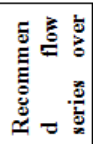 & 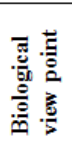 & 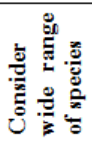 & 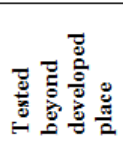 \\
\hline \multirow{7}{*}{$\begin{array}{l}\text { Hydrological } \\
\text { methods }\end{array}$} & Tennent method & $\checkmark$ & $\checkmark$ & $\checkmark$ & $x$ & $x$ & $\checkmark$ & $\checkmark *$ & $\checkmark$ & $x$ & $x$ & $x$ & $x$ \\
\hline & Tessman method & $\checkmark$ & $\checkmark$ & $\checkmark$ & $x$ & $x$ & $\checkmark$ & $\checkmark *$ & $\checkmark$ & $x$ & $x$ & $x$ & $x$ \\
\hline & FDC & $\checkmark$ & $\checkmark$ & $\checkmark$ & $x$ & $\checkmark$ & $\checkmark$ & $\checkmark *$ & $\checkmark$ & $\checkmark$ & $x$ & $x$ & $\checkmark$ \\
\hline & RVA & $x$ & $x$ & $\checkmark$ & $x$ & $\checkmark$ & $\checkmark$ & $x$ & $\checkmark$ & $x$ & $x$ & $x$ & $\checkmark$ \\
\hline & SBA & $\checkmark$ & $\checkmark$ & $\checkmark$ & $x$ & $x$ & $\checkmark$ & $\checkmark *$ & $\checkmark$ & $\checkmark$ & $x$ & $x$ & $x$ \\
\hline & BC Instream & $\checkmark$ & $\checkmark$ & $\checkmark$ & $x$ & $x$ & $\checkmark$ & $\checkmark *$ & $\checkmark$ & $x$ & $x$ & $x$ & $x$ \\
\hline & $\begin{array}{l}\text { Alberta } \\
\text { method }\end{array}$ & $\checkmark$ & $\checkmark$ & $\checkmark$ & $x$ & $x$ & $\checkmark$ & $\checkmark *$ & $\checkmark$ & $\checkmark$ & $x$ & $x$ & $x$ \\
\hline \multirow{3}{*}{$\begin{array}{l}\text { Hydraulic rating } \\
\text { methods }\end{array}$} & $\begin{array}{l}\text { Wetted perimeter } \\
\text { method }\end{array}$ & $\checkmark$ & $\checkmark$ & $\checkmark$ & $x$ & $x$ & $\checkmark * *$ & $\checkmark$ & $\checkmark$ & $x$ & $x$ & $x$ & $x$ \\
\hline & $\begin{array}{l}\text { Riffle analysis } \\
\text { method }\end{array}$ & $\checkmark$ & $\checkmark$ & $\checkmark$ & $x$ & $x$ & $\checkmark * *$ & $\checkmark$ & $\checkmark$ & $x$ & $x$ & $x$ & $x$ \\
\hline & Toe width method & $\checkmark$ & $\checkmark$ & $\checkmark$ & $x$ & $x$ & $\checkmark * *$ & $\checkmark$ & $\checkmark$ & $x$ & $x$ & $x$ & $x$ \\
\hline \multirow{2}{*}{$\begin{array}{l}\text { Habitat simulation } \\
\text { methods }\end{array}$} & HQI & $\checkmark$ & $\checkmark$ & $\checkmark$ & $x$ & $\checkmark$ & $\checkmark$ & $\checkmark$ & $\checkmark$ & $x$ & $\checkmark$ & $x$ & $x$ \\
\hline & IFIM & $x$ & $x$ & $x$ & $\checkmark$ & $\checkmark$ & $x$ & $x$ & $x$ & $\checkmark$ & $\checkmark$ & $x$ & $\checkmark$ \\
\hline \multirow[t]{3}{*}{ Holistic methods } & BBM & $x$ & $x$ & $x$ & $\checkmark$ & $\checkmark$ & $x$ & $x$ & $x$ & $\checkmark$ & $\checkmark$ & $\checkmark$ & $\checkmark$ \\
\hline & DRIFT & $x$ & $x$ & $x$ & $\checkmark$ & $\checkmark$ & $x$ & $x$ & $x$ & $\checkmark$ & $\checkmark$ & $\checkmark$ & $\checkmark$ \\
\hline & DRM & $x$ & $x$ & $x$ & $\checkmark$ & $\checkmark$ & $x$ & $x$ & $x$ & $\checkmark$ & $\checkmark$ & $\checkmark$ & $\checkmark$ \\
\hline
\end{tabular}

* indicates that though they required only hydrological data, they need reliable data; $* *$ indicates that they need some amount of field work.

There are numerous methods to assess EF under each category. Each category represents a wide range of methods from simple to complex and a comprehensive hydrological methods may be reliable than a less comprehensive holistic method. As a general view, holistic methods are the most reliable (King and Tharme, 2008; O'Keeffe et al., 2012, Gopal, 2013; Linnansari, 2013). However, they needa considerable amount of resources. Among holistic methods, Building Block Methodology (BBM) is the widely used successful method in many parts of the world because of its simplicity, reliability, flexibility, robust nature and strong 
recommendations (O'Keeffe et al., 2012) and also it is well documented (King and Tharme, 2008). Though BBM is a simple method compared to other holistic methods, it requires much of resources such as financial, technical, expert knowledge and time. Therefore, there is a requirement of a reliable method to assess EFs which consider whole riparian community while consuming fewer resources.

\section{Novel approach to assess environmental flows}

Building Block Methodology (BBM) is categorized under holistic methods (King et al., 2008) and has been identified as the most reliable and suitable to be studied further. However, the major limitation of the BBM is the high amount of data, resources and expert knowledge requirement. Lack of data availability can be the main obstacle in application of BBM for Sri Lankan situation. This study identified the need to bridge this gap by identifying simple minimum data requirement approaches. As a result, a novel approach was developed for EFA based on BBM focusing minimum data requirement concept. Figure 2 presents the framework of BBM. The conceptual framework of the proposed novel methodology for EFA is presented in Figure 3.

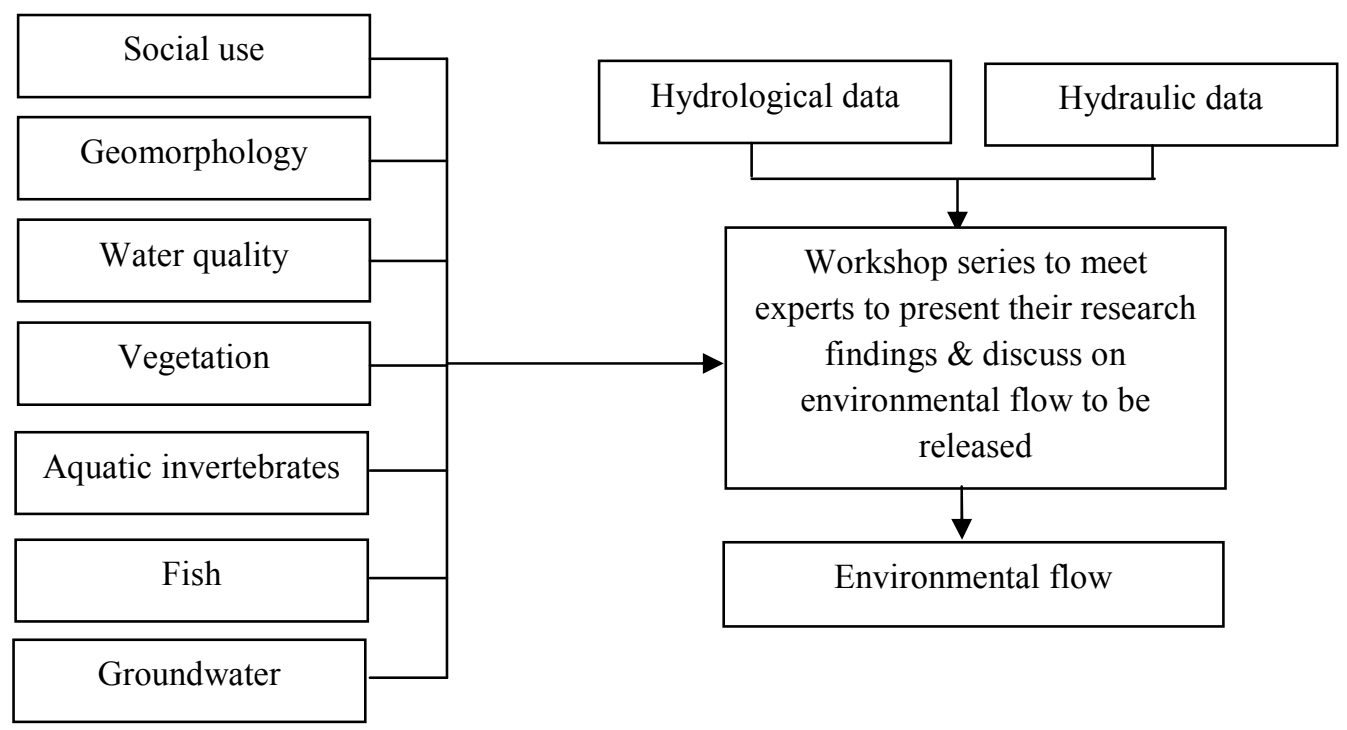

Fig. 2. The Building Block methodology 


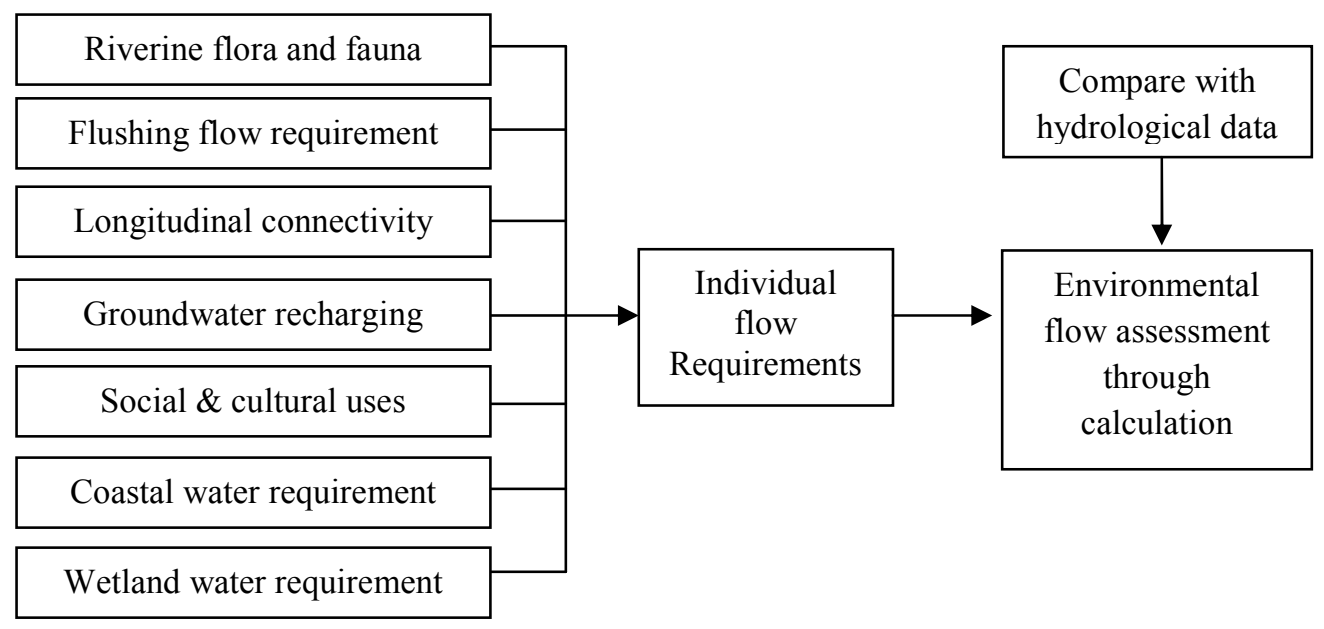

\section{Fig. 3. New approach to assess EF based on BBM}

Fish, vegetation and aquatic invertebrates are assessed separately in BBM. In the new approach, all of them were brought under one category called "Riverine flora and fauna". The Water quality parameter in BBM is termed as "Flushing flow requirement" broadening the view. BBM interested on Social water use and novel approach identified it as the "Social and Cultural water use" since many cultural events are associated with rivers. In calculating each EF components, new approaches were proposed to minimize the resource consumption through workshop series as well as field data collection.

The proposed new method is described below. To facilitate the process of EF estimation, the river is divided in to several segments. Then water requirement of each identified water user within each reach is assessed to determine the EF.

\section{Segmentation of the river reach}

Characteristics of the riparian zone can be very diverse along the river. It is useful to identify this diversity, i.e. land use, river morphological characters etc. and segment the river reach accordingly. Homogenous zones can be identified using remotely sensed data such as aerial photos or satellite images. This will facilitate EF calculation with lessfield data collection. Three alternatives were proposedto identify the width of the riparian zone.

1) Demarcation of the actual boundary of riparian vegetation using freely available remotely sensed data (satellite images).

2) Use of recommended river reservation area.

3) Identification of the riparian width using the dependence of community for river water (using preliminary questionnaire survey, personal interviews etc.) especially in the case of water requirement calculation for social water use.

\section{Water requirement of riparian flora and fauna}

Vegetation is one of the foremost components of most riparian ecosystems. In this study, the following two alternatives are proposed to calculate their water requirement. In the first alternative, categories of flora species are counted in pre determined areas using a field survey in homogenous river segments. Then their water requirement is calculated based on the literature. Second alternative proposes to use high resolution remotely sensing data to identify the land use pattern and the area of each vegetation strip. Then the reference 
evapotranspiration is calculated using a mathematical model such as CROPWAT. Crop factor is determined according to the literature and verified with the opinion from experts. Other necessary data such as temperature, humidity, sun shine hours and wind speed are available from the Department of Agriculture in their climatic data collection. Subsequently, the vegetation water requirement is calculated assuming evapotranspiration equals to water requirement. The water requirement calculation of fauna can be considered negligible compared to flora (King et al., 2008).

\section{Social and cultural water use}

According to the definition (Brisbane Declaration, 2007), social water use is also one of the constitutes of EFs. At first, it is important to estimate the riparian population. The population density of each administrative division can be calculated with its population and area. Then it is possible to calculate the population within the riparian zone with calculated population density and area of each administrative zone located within the riparian zone. Afterwards, a questionnaire survey is conducted to identify the social and cultural water uses in the riparian zone. Then the total water requirement is estimated.

\section{Flushing flow requirements}

Good quality water is important for the sustainability of the ecosystems because flora and fauna strictly respond to water quality. Since water quality is directly linked to flow via dilution, flushing flow is required to maintain the water quality. In this respect, values of water quality parameters i.e. EC, pH, TDS, Dissolved Oxygen, Sodium, Potassium, Calcium, Magnesium, Alkalinity, Nitrate, Ammonium, Phosphate, Chloride, Sulphate and Fluoride, of current situation should be compared with a reference condition. Reference condition can be defined as the water quality in upstream river section to the flow alteration structure, selected river section which can be considered as not modified, irrigation water quality recommendations or water quality values obtained for the river before flow alteration. If existing water quality parameters do not exist within the range of water quality parameters of reference condition, the flushing flow requirement should be calculated using Equation 1.

If flow is to be calculated to flush away any given solute (X), in a particular month.

\section{Average flow to be released $=\frac{\text { Existing avg concentration of } X}{X \text { concentration at reference condition }} \times$ existing avg flow} (Eq. 1)

The highest value of the segment should be taken into account as the overall flushing flow requirement of the segment.

\section{Water requirement of identified major wetlands}

Dams have a greater ability to influence the downstream wetlands. Therefore, in this study, wetlands were identified as the vital ecosystems available in the downstream. Wetlands need water for themselves and to maintain connectivity with the river. The volume of the wetland can be calculated by using Equation 2 and 3 (Wiens, 2001). Data requirement of this equation is very less fulfilling the minimum data requirement concept.

If wetland surface area $<70 \mathrm{ha} ; \mathrm{V}=2.85 \mathrm{~A}^{1.22}$

If wetland surface area $>70$ ha; $V=7.1 \mathrm{~A}+9.97$

Where, $\mathrm{V}=$ Volume; $\mathrm{A}=$ Area 
It is important to identify the flow that can maintain the connectivity between wetland and river which ensures water supply to the wetland. Connective canal volume can be estimated either using field measurements or digital elevation models. Frequency of flooding is possible to find through key informant interviews to identify the timing of flow which is required to supply water to the wetlands.

\section{Groundwater}

Groundwater has a greater relationship and significant role in freshwater ecosystems and flowing river water nourishes the groundwater storage. Using hydrograph, the durations with no base flow is identified. The seepage rate of the area can be assumed as recharge within the identified durations.

\section{Longitudinal connectivity}

In some occassions stream is the only pathway of dispersion and link between habitat patches. Minimum water level to maintain the connectivity can be critically assessed based on the long profile, cross section areas in pre determined intervals, elevation and flow velocity or otherwise with Digital Elevation Models. Natural flow pattern is very important to be considered to know the presence of no flow days. The maximum flow to maintain longitudinal connectivity in a particular location would be considered as the flow requirement for longitudinal connectivity for a particular month.

\section{Coastal water requirements}

Coastal areas consist of specific ecosystems including mangroves, coastal lagoons and many aquatic flora and fauna species. Recommended salinity range of sea water suitable for most abundant or critical crustaceans presence in the lagoon is possible to be found out with literature. Then recommended flow to be released for proper dilution in a particular month should be calculated using Equation 3.

\section{Recommended flow allocation $=\frac{\text { Present salinity }}{\text { Recommended salinity }} \times$ Present inflow}

To estimate water requirement for mangroves, same procedure should be followed as proposed under riverine flora.

\section{Method of finalizing environmental flow}

Water requirement for all the consumptive and non consumptive uses should be summed up separately. If the consumptive uses are higher than non consumptive uses, summation of water requirement for consumptive uses should be released as EF or vice versa.

Subsequently, the EF was assessed using the approaches proposed. When consider a specific river or a segment, all the EF components which are coming under proposed method are not equally important. In this study, only the most relevant components to the river segment of DeduruOya were quantified.

\section{RESULTS AND DISCUSSION}

\section{Flow pattern of DeduruOya}

Ecosystems are adapted to the general flow pattern of the river therefore, identification of the natural flow regime is important. Figure 1 presents the flow pattern of DeduruOya at 
RidiBendi Ella located immediate downstream of the dam, before and after the dam construction. Average flow was calculated using daily flow data collected during 2003-2013. Filling of DeduruOya reservoir was started in November, 2013 and opened for public in November, 2014. Therefore, it was not possible to get a longer time series to assess the flow pattern after dam construction. The natural flow shows a bimodal pattern corresponding to the two rainfall seasons. However, there is a considerable change to the natural flow pattern after the dam construction. Though the bimodal pattern is still prominent after the dam construction, very high rainfall received during November, 2014 led the gates to be opened so the downstream flow has increased sharply. This may not happen regularly with normal rainfall in the area. However, the extreme rainfall events can bring adverse impacts to the downstream environments. It is evident that during the dry periods, RidiBendi Ella records a very low flow which is further disturbed by the dam construction. Hence, there is a necessity to assess the EF requirement to supply adequate flow to the downstream to sustain the ecosystems.

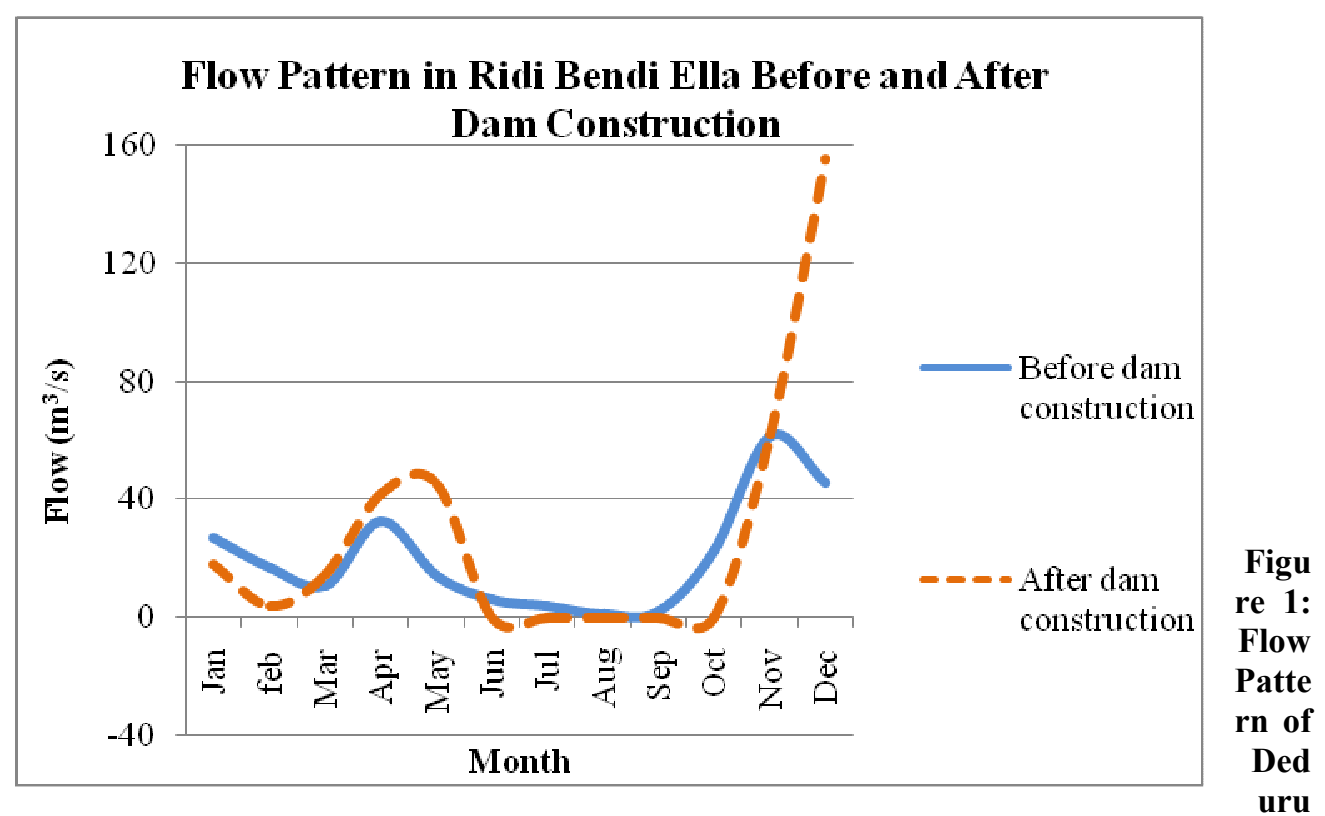

Oya at RidiBendi Ella during the period of 2003-2013

\section{Segmentation of the river}

Homogenous zones in the riparian zone were identified using visual interpretation of high resolution QuickBirdsatellite imagesavailable in Google Earth and by field verification. Spreading of natural vegetation was considered to identify the width of the riparian zone. The river reach is segmented in to three as zone 1 which is dominating by dense natural riparian vegetation, zone 2 which is dominating by dry open land, paddy fields and croplands and finally zone 3 which is dominating by coastal area and human settlements (Figure 4). 


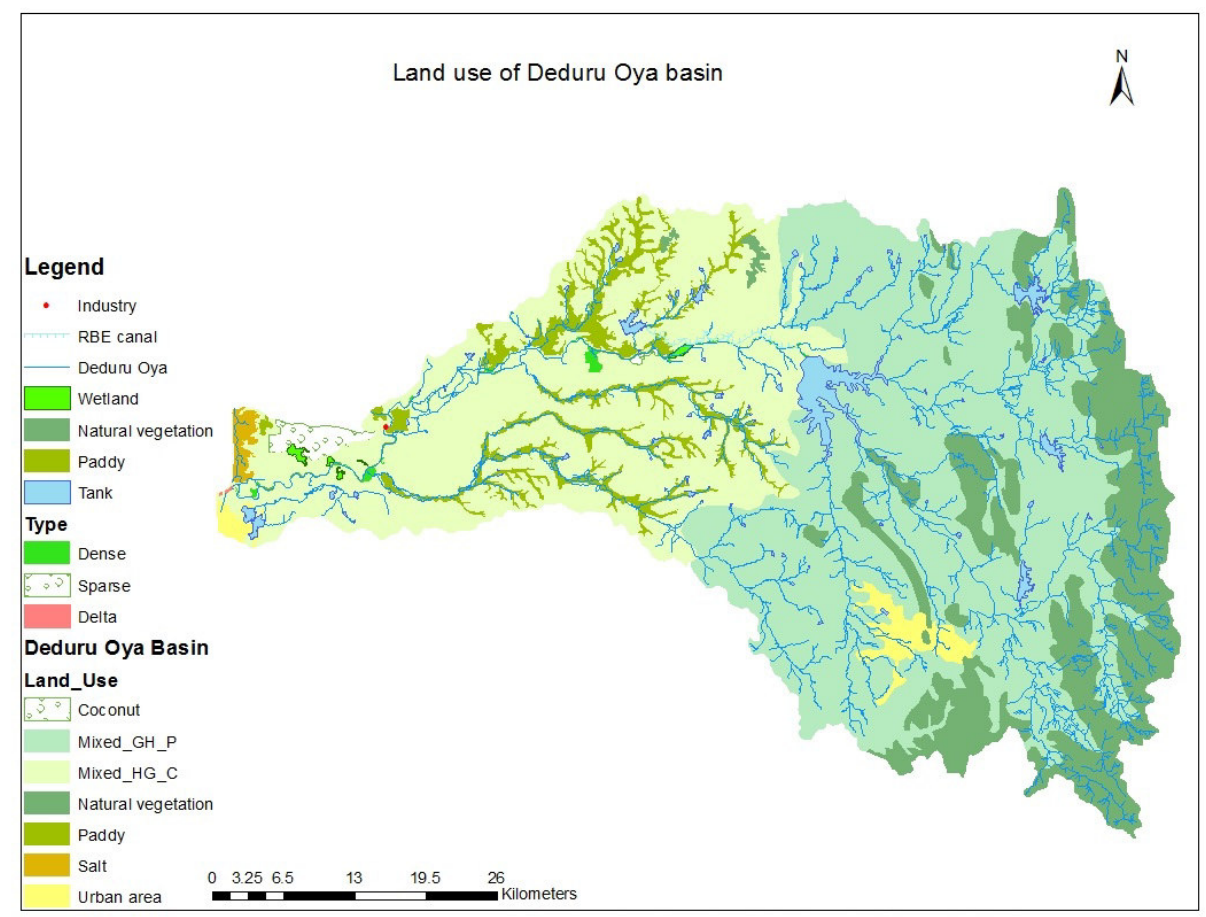

Fig. 4. Land use pattern of DeduruOya basin and Segmentation of river reach downstream of DeduruOya reservoir

\section{Assessment of individual EF components}

Vegetation water requirement

At first, the study area was mapped to identify the natural vegetation and land use pattern (Figure 4) using ArcGIS software. Natural vegetation is present only in a very narrow strip along the river when it considers the area downstream to the DeduruOya reservoir.

The riverine vegetation strip was divided into two types as dense vegetation and sparse vegetation according to the canopy density using land cover information. The Crop Factors (Kc) of each vegetation type were obtained by expert judgment. Reference evapotranspiration (ETo) was obtained by CROPWAT 8.0 model to calculate Crop Evapotranspiration. Finally, the Crop Evapotranspiration was termed as water requirement assuming that Crop Evapotranspiration rate equals to crop water requirement and there is no water deficit(Table 2).

Table 2. Calculation of total water requirement of riparian vegetation

\begin{tabular}{|c|c|c|c|}
\hline Month & $\begin{array}{l}\text { Water requirement } \\
(W R) \text { of dense } \\
\text { vegetation }\left(\mathbf{m}^{3} / \text { day }\right)\end{array}$ & $\begin{array}{c}\text { Water requirement of } \\
\text { sparse vegetation } \\
\left(\mathrm{m}^{3} / \text { day }\right)\end{array}$ & $\begin{array}{c}\text { Water requirement of } \\
\text { riparian vegetation } \\
\left(\mathbf{m}^{3} / \text { day }\right)\end{array}$ \\
\hline & $\begin{array}{c}\mathbf{W R}_{\text {dense }}=\mathbf{E T o} \times \mathbf{K c} \times \\
\text { area }\end{array}$ & $\begin{array}{c}\mathbf{W R}_{\text {sparse }}=\mathbf{E T o} \times \mathrm{Kc} \times \\
\text { area }\end{array}$ & $\mathbf{W R}_{\text {dense }}+\mathbf{W} \mathbf{R}_{\text {sparse }}$ \\
\hline Jan & 31444.08 & 6811.195 & 38255 \\
\hline
\end{tabular}




\begin{tabular}{|l|c|c|c|}
\hline Feb & 35062.96 & 7595.092 & 42658 \\
\hline Mar & 38199.33 & 8274.47 & 46474 \\
\hline Apr & 36671.35 & 7943.491 & 44615 \\
\hline May & 38360.17 & 8309.309 & 46669 \\
\hline Jun & 34580.44 & 7490.572 & 42071 \\
\hline Jul & 32972.05 & 7142.174 & 40114 \\
\hline Aug & 35786.74 & 7751.872 & 43539 \\
\hline Sep & 36028 & 7804.131 & 43832 \\
\hline Oct & 32087.43 & 6950.554 & 39038 \\
\hline Nov & 27101.42 & 5870.518 & 32972 \\
\hline Dec & 24930.09 & 5400.18 & 30330 \\
\hline
\end{tabular}

\section{Social water use}

Social water use was assessed using a questionnaire survey. Then the average water abstraction of the sample in each month in each zone was calculated and it was used to calculate the total water abstraction of the population. Water abstraction in each zone was summed up to estimate the total monthly water abstraction from DeduruOya (Table 3).

Table 3. Water abstraction from DeduruOya for social use

\begin{tabular}{|c|c|c|c|c|}
\hline \multirow[t]{2}{*}{ Month } & \multicolumn{3}{|c|}{ Water abstraction in each zone ( $\mathbf{m}^{3} /$ month) } & \multirow{2}{*}{$\begin{array}{c}\begin{array}{c}\text { Total water } \\
\text { abstraction }\end{array} \\
\mathbf{m}^{3} / \text { day } \\
\end{array}$} \\
\hline & Zone 1 & Zone 2 & Zone 3 & \\
\hline Jan & 7984.761 & 19328.29 & 18279.51 & 1520 \\
\hline Feb & 8484.037 & 24061.19 & 16874.22 & 1650 \\
\hline Mar & 8075.054 & 20964.27 & 15994.57 & 1500 \\
\hline Apr & 9139.919 & 18238.62 & 15994.57 & 1450 \\
\hline May & 4734.391 & 19211.7 & 17452.43 & 1380 \\
\hline Jun & 9736.63 & 22477.35 & 16874.22 & 1640 \\
\hline Jul & 7857.88 & 23702.16 & 16874.22 & 1615 \\
\hline Aug & 7747.304 & 26184.66 & 16874.22 & 1690 \\
\hline Sep & 4106.739 & 21946.95 & 15994.57 & 1400 \\
\hline Oct & 4734.391 & 17864.51 & 16343.21 & 1300 \\
\hline Nov & 4734.391 & 18235.17 & 17523.23 & 1350 \\
\hline Dec & 4734.391 & 19025.11 & 17523.23 & 1375 \\
\hline
\end{tabular}

It was asked from the people about the average minimum water height in river they need to fulfill their needs. Average river water height required for non consumptive uses does not 
exceed the height for consumptive uses. Therefore, the non consumptive water uses are fulfilled when it releases water for consumptive uses.

\section{Flushing flow requirements}

According to the flow pattern of DeduruOya, it has two high flow seasons and a very low or no flow season during dry periods. Even after the dam construction, this nature has not changed considerably. Therefore, it was assumed that there is no requirement of assessing flushing flow requirement for DeduruOya.

\section{Wetlands}

Wetland water requirement was not considered in this study because there are no any identified natural wetlands within the DeduruOya basin (Survey Department, 2007).

\section{Groundwater}

Groundwater recharge was not accounted in this study because of two reasons. The downstream section of the river is fed by groundwater. Second one is that the upstream section (just below the reservoir) only carries very small flow in dry season allowing less recharge and a large flow during wet season even after the dam construction. A substantial flow is still being released even after the dam. Therefore, there is no additional requirement of flow to recharge groundwater.

\section{Longitudinal connectivity}

In the downstream, the longitudinal connectivity is always there even after dam construction. Naturally, in upstream DeduruOya is characterized by a large peak in wet season and very less flow in dry season and this nature has not changed even after dam construction. In wet season, there is longitudinal connectivity because of enough flow release. In dry spells, the tiny flow is unable to keep longitudinal connectivity even naturally. Therefore, water allocation for longitudinal connectivity was not considered in this study.

\section{Coastal water requirements}

There are no identified coastal wetlands within DeduruOya basin hence not considered in calculations.

\section{Environmental flow requirement of DeduruOya}

The total requirement of EF was assessed by compiling social and vegetation water use. As shown in Table 4, the EF as a percentage of the natural flow is less than $10 \%$ in 9 months of a year. The requirement of EF is high during the months of July, August and September. In the peak month of August, about half of the natural flow has to be released as environmental flow.

Table 4. Environmental flow downstream of DeduruOya reservoir

\begin{tabular}{|l|c|c|c|c|}
\hline Month & $\begin{array}{c}\text { Social water } \\
\text { use (m3/day) }\end{array}$ & $\begin{array}{c}\text { Vegetation } \\
\text { water use } \\
\mathbf{( m 3 / d a y )}\end{array}$ & $\begin{array}{c}\text { Environmental } \\
\text { flow (l/s) }\end{array}$ & $\begin{array}{c}\text { EF as a } \\
\text { percentage of } \\
\text { RBE natural } \\
\text { flow (\%) }\end{array}$ \\
\hline January & 1519.752 & 38255.27 & 460 & 1.89 \\
\hline February & 1647.315 & 42658.05 & 510 & 3.72 \\
\hline March & 1501.13 & 46473.8 & 555 & 5.46 \\
\hline
\end{tabular}




\begin{tabular}{|l|c|c|c|c|}
\hline April & 1445.77 & 44614.84 & 530 & 1.96 \\
\hline May & 1379.951 & 46669.48 & 555 & 3.07 \\
\hline June & 1636.273 & 42071.02 & 505 & 9.26 \\
\hline July & 1614.475 & 40114.22 & 480 & 13.61 \\
\hline August & 1693.539 & 43538.61 & 520 & 51.42 \\
\hline September & 1401.609 & 43832.13 & 520 & 29.91 \\
\hline October & 1298.071 & 39037.99 & 465 & 2.00 \\
\hline November & 1349.76 & 32971.94 & 400 & 0.64 \\
\hline December & 1376.091 & 30330.27 & 365 & 0.66 \\
\hline
\end{tabular}

International Water Management Institute (IWMI) has developed a model for a quick EFA for major rivers in Sri Lanka, named as Sri Lanka Environmental Flow Calculator. This model is capable to assess EF with default data set or user fed data set. The Sri Lanka Environmental Flow Calculator uses the shifting flow duration curve method for the assessment. Shifting flow duration curve is based on flow duration curve developed upon fixed 17 points of $x$ axis. Determination of the Environmental Management Class (also termed as Ecological Management Class) (EMC) of a particular basin is important to be considered. Class A refers to a natural basin, Class B refers to slightly modified basin, class $\mathrm{C}$ refers to moderately modified basin, class $\mathrm{D}$ refers to largely modified basin, class $\mathrm{E}$ refers to seriously modified basin and class $\mathrm{F}$ refers to critically modified basin. In this study, EF was assessed with both default data set (1969 - 1979) with EMC-B and user fed data set (2003 - 2013) with EMC-C. EF assessed by model with default data set and user fed data set was compared with the EF assessed by new method (Table 5).EF assessed by model with default data set and user fed data set was compared with the EF assessed by MIREFA, using $\mathrm{t}$ test. The $\mathrm{t}$ values obtained were 0.002 and 0.019 respectively for default data set and user defined data set.

This shows that there is a significant difference at 0.05 probability level between EF estimation using the proposed method and the Sri Lanka EF Calculator.The Sri Lanka EF calculator model is based only on the hydrological data while MIREFA depends on water requirement of each identified water users. Therefore, recommended EF using two methods can be different. The significant difference observed between EF calculated using IWMI EF calculator for default and user defined data set may be due to the reason that there may be considerable variation in environmental condition and hydrological characteristics between two time periods. Since MIREFA is based on data collected in the field, a relatively high accuracy can be expected from this method. However, further assessment should be carried out and comparisons should be made to improve the MIREFA.

Table 5. Environmental Flow assessed by Sri Lanka Environmental Flow Calculator model and the Environmental Flow assessed by new method

\begin{tabular}{|c|c|c|c|}
\hline Month & $\begin{array}{l}\text { model EF default data } \\
-\mathrm{EMC}-\mathrm{B}\left(\mathrm{m}^{3} / \mathrm{s}\right)\end{array}$ & $\begin{array}{l}\text { model EF user defined } \\
\text { data - EMC-C }\left(\mathrm{m}^{3} / \mathrm{s}\right)\end{array}$ & $\begin{array}{l}\text { MIREFA calculated } \\
\mathrm{EF}\left(\mathrm{m}^{3} / \mathrm{s}\right)\end{array}$ \\
\hline January & 1.713 & 5.722 & 0.460 \\
\hline February & 0.926 & 2.807 & 0.513 \\
\hline March & 0.290 & 1.602 & 0.555 \\
\hline April & 0.673 & 6.978 & 0.533 \\
\hline
\end{tabular}




\begin{tabular}{|l|r|r|r|}
\hline May & 0.950 & 3.473 & 0.556 \\
\hline June & 1.108 & 0.349 & 0.506 \\
\hline July & 0.969 & 0.235 & 0.483 \\
\hline August & 0.518 & 0.002 & 0.524 \\
\hline September & 0.017 & 0.042 & 0.524 \\
\hline October & 0.648 & 3.944 & 0.467 \\
\hline November & 1.069 & 13.523 & 0.397 \\
\hline December & 1.083 & 13.995 & 0.367 \\
\hline
\end{tabular}

\section{CONCLUSIONS}

Among many EFA methods available, Holistic approach is identified as the best method category. Building Block Methodology is considered as the most reliable, accurate and most applied method among the Holistic approach. However, these reliable methods have never been used in Sri Lanka due to data and resource limitations. Therefore, a new EFA was developed in this study to address this gap, based on minimum data requiring concept. However, it is suggested to improve this method by further assessments and comparisons with already established methods.

\section{ACKNOWLEDGEMENT}

This work was carried out with the aid of a grant from the International Development Research Center, Ottawa, Canada. Their financial support is greatly acknowledged.

\section{REFERENCES}

Brisbane Declaration, (2007). The Brisbane Declaration: Environmental Flows Are Essential for Freshwater Ecosystem Health and Human Well-Being. Declaration of the 10th International River Symposium and International Environmental Flows Conference, 3-6 September 2007, Brisbane, Australia.

Dyson, M., Bergkamp, G. and Scanlon, J. (2003) Flow, The Essentials of Environmental Flows. IUCN, Gland, Switzerland and Cambridge, UK.

Gopal, B. (2013). Environmental flows: An introduction for water resource managers. National Institute of Ecology, New Delhi.

King. J.M., Tharme, R.E. and Villiers, M.S. (2008) Environmental Flow Assessment for Rivers: Manual for the Building Block Methodology. Water Research Commision, Republic of South Africa.

Linnansari, T., Monk, W.A. and Curry, R.A. (2013). Review of approaches and methods to assess environmental flows across Canada and internationally [online]. [Accessed on 16.01.2015]. Available at http://www.dfo-mpo.gc.ca/library/348885.pdf 
O'Keeffe, J and Le Quesne, T (2009). Keeping Rivers Alive; APrimeron Environmental Flows and Their Assessment.

O'Keeffe, J., Kaushal, Bharati, L. and Smakhtin, V. (2012) Assessment of Environmental Flows for the Upper Ganga Basin. World Wide Fund for nature -India.

Richter, B.D., Baumgartner, J.V.B., Wigington, R. and Braun, D.P. (1997). How much water does a river need?.Fresh water Biology.

Silva, E. I. L., Manthrithilake, H., Pitigala, D. and Silva, E. N. S. (2014). Environmental flow in Sri Lanka: ancient anicuts versus modern dams. Sri Lanka Journsl of Aquatic Scence.vol 19 , pp 3-14

Smakhtin, V. and Anputhas, M. (2006).An Assessment of Environmental Flow Requirements of Indian River Basins. Research Report 107. International Water Management Institute Colombo, Sri Lanka.

Smakhtin, V. and Weragala, N. (2005). An assessment of hydrology and environmental flows in the Walawe river basin, Sri Lanka.Working Paper 103. International Water Management Institute (IWMI), Colombo, Sri Lanka

Survey department Of Sri Lanka, (2007).The national atlas of Sri Lanka.Survey department of Sri Lanka, Colombo. ISBN 955-9059-04-1

UNEP, (2003). Ecosystems and human well being: A framework for assessment [online]. [Accessed on 14.01.2015]. Available at http://www.unep.org/maweb/documents/document.300.aspx.pdf

WCD (World commission on dams), (2000). Dams and development, A new framework for decision making. Earthscan publications Ltd, London.

Wiens, L. H. (2001). A Surface Area-Volume Relationship for Prairie Wetlands in the Upper Assiniboine River Basin, Saskatchewa.Canadian Water Resources Journal. Taylor \& Francis, London. 